\title{
Interhormonal Correlations at Professional Risk Staffs
}

\author{
Roman V. Kubasov, $\mathrm{PhD}^{1}$; Yury E. Barachevsky, $\mathrm{PhD}, \mathrm{ScD}^{1}$; Andrey M. Ivanov, $\mathrm{PhD}, \mathrm{ScD}^{2}$; \\ Elena D. Kubasova, $\mathrm{PhD}^{1}$; Valery V. Lupachev, $\mathrm{PhD}, \mathrm{ScD}^{1}$ \\ ${ }^{I}$ Northern State Medical University, Archangelsk, the Russian Federation \\ ${ }^{2}$ Kirov Military Medical Academy, Saint Petersburg, the Russian Federation
}

\begin{abstract}
Background: To adapt quickly to changes in the environment, significant functional changes occur in the human body exposed to various negative factors (including extreme occupational stress). The endocrine system, with the activation of the sympathoadrenal and pituitary-adrenocortical axis, plays an important role in this process. The aim of our investigation was to study the features of interhormonal relationships between the sympathoadrenal and pituitary-adrenocortical axis and the thyroid and gonadal hormones among professional, at-risk staff.

Materials and Methods: A total of 156 police officers stationed in the Archangelsk region were examined. Depending on their professional activity, 3 groups were formed. Group 1 included 48 police officers who were sent to the conflict regions to maintain law enforcement - combatants. Group 2 included 52 duty officers who had never been in a territory with military conflict. Group 3 was formed from 56 students of the Police Training Center. Spearman's rank correlation coefficient was calculated to measure the strength and direction of the relationship between two variables.

Results: Among the studied groups of police officers, we found that the severity of interhormonal correlation depended on the intensity of professional activity. The highest number of significant interhormonal correlations was registered in the group of combatants, and these correlations were recorded between the hormones of all parts of the endocrine system: pituitarysympathoadrenal and thyroid-gonad hormones.

Conclusion: The revealed multiple significant intersystem hormonal correlations among combatants, as compared with duty and student policemen, indicate that the functional intensity of the endocrine system is due to the extreme state of the professional environment. (International Journal of Biomedicine. 2019;9(2):187-189.)
\end{abstract}

Key Words: professional risk • interhormonal relationships • adaptation

\section{Introduction}

To adapt quickly to changes in the environment, significant functional changes occur in the human body exposed to various negative factors (including extreme occupational stress). The endocrine system, with the activation of the sympathoadrenal and pituitary-adrenocortical axis, plays an important role in this process. ${ }^{(1,2)}$

Police officers usually carry out professional tasks in extreme conditions, and sometimes in emergency cases. The intensity and duration of exposure to negative factors contribute to the emergence of various disorders, including functional changes or stable pathological conditions, with a decrease in the quality of life. ${ }^{(3,4)}$

*Corresponding author: Roman Koubassov, PhD. Northern State Medical University.Archangelsk, Russia.E-mail: romanas2001@gmail.com
The aim of our investigation was to study the features of interhormonal relationships between the sympathoadrenal and pituitary-adrenocortical axis and the thyroid and gonadal hormones among professional, at-risk staff.

\section{Materials and Methods}

A total of 156 police officers stationed in the Archangelsk region were examined. Depending on their professional activity, 3 groups were formed. Group 1 included 48 police officers who were sent to the conflict regions to maintain law enforcement combatants. Group 2 included 52 duty officers who had never been in a territory with military conflict. Group 3 was formed from 56 students of the Police Training Center.

The serum levels of adrenaline (Adr), noradrenaline (Nadr), adrenocorticotropin (ACTH), prolactin (Prol), thyroidstimulating hormone (TSH), follicle-stimulating hormone (FSH), 
luteotropin ( $\mathrm{LH})$, cortisol (Cort), thyroxine $\left(\mathrm{T}_{4}\right)$, triiodothyronine $\left(\mathrm{T}_{3}\right)$, testosterone (Tstr), estradiol (Estr) and progesterone (Prog) were measured by radioimmunoassay methods.

Statistical analysis was performed using the statistical software «Statistica». (v6.0, StatSoft, USA). Spearman's rank correlation coefficient was calculated to measure the strength and direction of the relationship between two variables.

\section{Results and Discussion}

Results of correlation analyses in the investigated groups are presented in Figure 1. In Group 1 (Fig. 1a), we found significant correlations between the following parts of the endocrine system: pituitary gland-adrenal glands, pituitary gland-thyroid gland, pituitary gland-gonads. We found many inverse correlations with norepinephrine: Nadr-Prol $\left(R^{2}=-0.45\right), N_{a d r}-T_{3}\left(R^{2}=-0.36\right)$ and one positive - Nadr-Estr $\left(\mathrm{R}^{2}=0.39\right)$. At the same time, for adrenaline, only one inverse correlation with LH was revealed $\left(\mathrm{R}^{2}=-0.38\right)$. Pituitaryadrenocortical hormones quite significantly correlated with sex steroids and thyroid hormones: ACTH-Estr $\left(\mathrm{R}^{2}=0.35\right)$, Cort-Tstr $\left(\mathrm{R}^{2}=0.46\right)$ and Cort-TSH $\left(\mathrm{R}^{2}=0.37\right)$. In addition, Estr positively correlated with $\mathrm{T} 4\left(\mathrm{R}^{2}=0.37\right)$.

a)

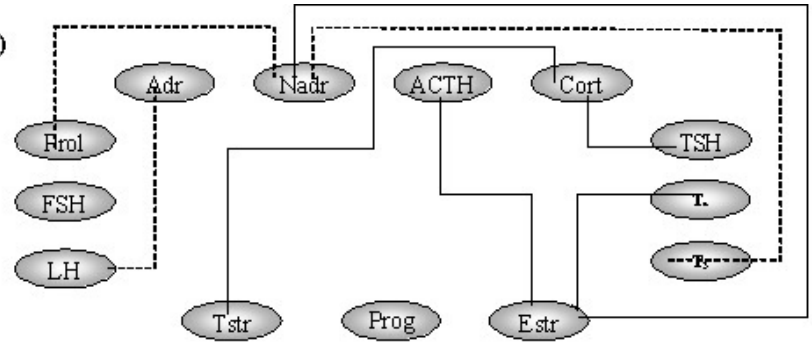

b)

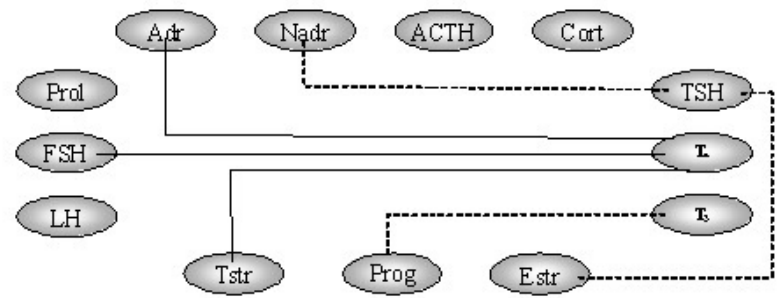

c)

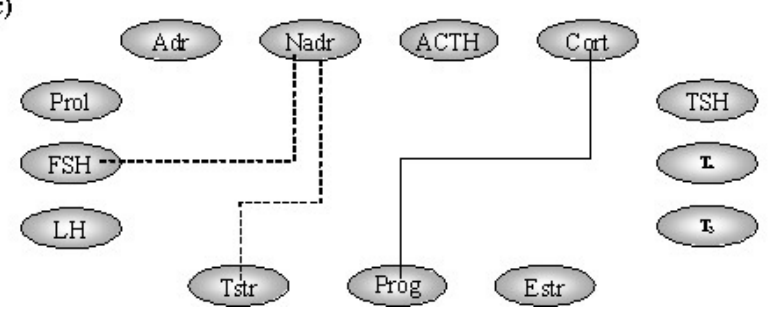

Fig. 1.

The significant interhormonal correlations in different police officer groups: a) combatants; b) duty officers; c) students of the Police Training Center. Solid lines - positive correlations, dotted lines-inverse correlations
In Group 2 (Fig.1b), significant hormonal correlations were detected between sympathoadrenal and thyroid parts of the endocrine system: Adr- $\mathrm{T}_{4}\left(\mathrm{R}^{2}=0.38\right)$ and Nadr-TSH $\left(\mathrm{R}^{2}=-0.44\right)$. We did not find significant correlations between pituitary-adrenocortical hormones and the sex steroids and thyroid hormones. However, the pituitary-thyroid and pituitary-gonad hormones significantly correlated: TSH-Estr $\left(\mathrm{R}^{2}=-0.36\right), \mathrm{T} 3-\mathrm{Prog}\left(\mathrm{R}^{2}=-0.34\right), \mathrm{T} 4-\mathrm{FSH}\left(\mathrm{R}^{2}=0.28\right)$, and T4Estr $\left(\mathrm{R}^{2}=0.50\right)$.

In Group 3 (Fig.1c), we found a small number of correlations between the studied hormones: Nadr-FSH $\left(\mathrm{R}^{2}=-\right.$ $0.38)$, Nadr-Tstr $\left(\mathrm{R}^{2}=-0.36\right)$, and Cort-Prog $\left(\mathrm{R}^{2}=0.30\right)$.

So, among the studied groups of police officers, we found that the severity of interhormonal correlation depended on the intensity of professional activity. The highest number of significant interhormonal correlations was registered in the group of combatants, and these correlations were recorded between the hormones of all parts of the endocrine system: pituitary-sympathoadrenal and thyroid-gonad hormones. In the group of duty officers, the number of significant correlations was significantly less compared to that of combatants. In particular, the significant links of the pituitary-adrenocortical axis (ACTH, cortisol) with the hormones of the thyroid and sex glands were turned off. In the group of students, the number of significant correlations was minimal. In particular, the thyroid gland was excluded from the significant interhormonal ensemble. The sympathoadrenal part was only partially presented: norepinephrine significantly correlated with FSH and testosterone. One correlation for cortisol with progesterone was found. Our findings agree with other results of investigations into endocrine functional conditions in professional, at-risk staff. ${ }^{(5-7)}$

\section{Conclusion}

The revealed multiple significant intersystem hormonal correlations among combatants, as compared with duty and student policemen, indicate that the functional intensity of the endocrine system is due to the extreme state of the professional environment.

\section{Competing Interests} interests.

The authors declare that they have no competing

\section{References}

1. Kino T, Charmandari E, Chrousos GP. Disorders of the Hypothalamic-Pituitary-Adrenocortical System. In Fink G, Pfaff D.W., Levine J, editors. Handbook of Neuroendocrinology. USA, NY: Academic Press; 2012:639-657.

2. Poskotinova LV, Demin DB, Krivonogova EV. Short-term HRV Biofeedback: Perspectives in Environmental Physiology and Medicine. International Journal of Biomedicine. 2017;7(1):24-7. doi: 10.21103/Article7(1)_RA3.

3. Koubassov R, Barachevsky Yu, Yuriev Yu. Hypophysisthyroid regulation features at different professional lawenforcement officer groups. International Journal of 
Collaborative Research on Internal Medicine and Public Health. 2012;4(5):707-12.

4. Polovov CF, Antonyuk MV, Andryukov BG. Pituitaryadrenal system of soldiers of the pacific fleet in the initial period of service. Marine Medicine. 2016;2(3):84-91. doi: 10.22328/2413-5747-2016-2-3-84-91. [Article in Russian].

5. Koubasov RV, Barachevsky YuE, Lupachev V. Adrenocorticotropic hormone and cortisol secretion changes among the law enforcement personnel during the mission to the areas of armed conflicts. International Journal of Biomedicine. 2014; 4(2):76-8.
6. Tipisova EV, Gorenko IN, Popkova VA, Elfimova AE. Dmitry S. Potutkin DS, Andronov SV, et al. The Relationship between Blood Thyroid Hormone and Dopamine Levels in Residents of the Arctic Regions of Russia. International Journal of Biomedicine. 2019;9(1):43-7.doi: 10.21103/ Article9(1)_OA8.

7. Zuikova AA, Potemina TE, AV, Pereshein AA, Kuznetsova SV. Development of psychosomatic disorders after suffering combat stress. Russian Osteopathic Journal. 2018;(3-4):717. doi: 10.32885/2220-0975-2018-3-4-71-77. [Article in Russian]. 